\title{
Penumbuhan Jiwa Wirausaha Siswa SMK Ma'arif NU 01 Wanasari Melalui Pelatihan Pengolahan Limbah Air Kelapa
}

\author{
Muhamad Hasdar ${ }^{1}$, Abdul Bashar ${ }^{2}$, Wadli $^{3}$ \\ ${ }^{123)}$ Universitas Muhadi Setiabudi, Brebes, Jawa Tengah, Indonesia \\ 1*Email: hasdarmuhammad@umus.ac.id \\ ${ }^{2}$ Email: abdulbashar@umus.ac.id \\ ${ }^{3}$ Email: wadliumus@umus.ac.id
}

\begin{abstract}
Entrepreneurship development among productive young people is a strategic program to build young entrepreneurs who have quality human resources. Vocational students are a strategic choice for building young entrepreneurs. The purpose of this community development activity is 1) Building strong character, because strong character becomes the main capital to become an entrepreneur in facing the challenges of changes that occur in his life. 2) Vocational students have skills to process coconut water waste into nata de coco. 3) Vocational students can start opening new business opportunities either before or after graduating later. The partners of this activity are students from SMK Ma'arif NU 01 Wanasari who are selected 20 students, their have an interest in food entrepreneurship. This activity was carried out in four stages for 2 months. Activities are divided into 4 stages. stage I is measuring the level of understanding from the students about entrepreneurship by giving quisioners, stage II is a process transfer knowlegde with the lecture method, stage III is carried out with the practice of directly using appropriate technology, stage VI is the evaluation stage of activities with quisioner and lecture methods. All vocational students participate in all stages of the training well, with this entrepreneurship training vocational students have increased skills and knowledge in entrepreneurship. Through these activities vocational students also have the skills to process coconut water waste into nata de coco until the packaging process is ready to be marketed and vocational students have basic knowledge about starting entrepreneurship in the food sector. Based on the evaluation results of entrepreneurship training activities, Vocational students are very happy and satisfied and in accordance with the expectations of SMK students to build their entrepreneurial spirit.
\end{abstract}

Keyword: Entrepreneurship, Vocational students, nata de coco, training

\section{PENDAHULUAN}

Pengembangan wirausaha dikalangan anak muda produktif merupakan program strategis untuk membangun wirausaha muda yang mempunyai kualitas SDM yang bermutu. Peningkatan rasio wirausaha di Indonesia kita harus ditunjang oleh kualitas wirausaha muda. Siswa SMK merupakan salah satu pilihan strategis untuk membangun wirausaha muda. Potensi kaum muda dapat dioptimalkan melalui kewirausahaan dapat membentuk prilaku positif, karena siswa SMK memiliki daya juang dan semangat untuk mengolah sumberdaya yang ada disekitarnya sehingga lebih produktif. Siswa
SMK lebih cenderung terbuka terhadap pengetahuan baru dan memiliki pola pikir kritis dan semangat serta daya juang yang tinggi untuk mengoptimalkan sumber daya alam maupun sumber daya lainnya yang ada di wilayahnya.

Salah satu sumber daya yang belum termaksimalkan di daerah adalah limbah air kelapa yang berasal dari pedagang kelapa di pasar-pasar tradisional. Limbah air kelapa seyogyanya dapat diolah dengan metode sederhana menjadi nata de coco. Disisi lain pembuatan produk nata de coco juga dapat membantu mengatasi timbulnya pencemaran limbah air kelapa di pasar tradisional. 
Biasanya para pedagadang kelapa dipasar tradisional membuang limbahnya di selokan pasar yang pada akhirnya menimbulkan bau tidak sedap atau terkadang tergenang dan menimbulkan becek di pasar tradisional, maka pengolahan air kelapa menjadi nata de coco menjadi salah satu solusi sederhana. Pembuatan produk nata de coco dapat dilakukan oleh siswa SMK sebagai peluang usaha baru dengan memanfaatkan limbah air kelapa sebagai bahan baku utama. Nata de coco merupakan merupakan makan berserat berkalori rendah yang sangat familiar dan sangat digemari di masyarakat Indonesia. Biasanya nata de coco sering digunakan sebagai makanan pencuci mulut, bahan pencampur fruit cocktail, jelly, yogurt dan es krim (Nurdyansyah dan Widyastuti, 2017).

Penerimaan masyarakat akan produk nata de coco cukup baik. Hal ini dapat terlihat dari banyaknya variasi produk minuman dengan tambahan nata de coco yang biasa dipasarkan di toko-toko swalayan atau sebagai bahan pelengkap minuman es buah yang biasa dijual di kaki lima. Sehingga peluang pasar produk nata de coco yang dapat dikelola oleh anak SMK dengan model home industry.

Kegiatan pelatihan pengolahan limbah air kelapa menjadi nata de coco merupakan bentuk sosialisasi dan salah satu cara untuk memperkuat minat siswa SMK menjadi wirausaha muda khususnya di bidang pangan sehingga mampu memperkuat ekonomi rakyat. Mitra kegiatan ini yaitu siswa SMK Ma'arif NU 01 Wanasari Kabupaten Brebes. Kegitan pengabdian kepada masyarakat ini bertujuan untuk 1) membangun karakter yang kuat anak muda, karena karakter yang kuat menjadi modal utama menjadi seorang wirausaha muda dalam menghadapi tantangan perubahan yang terjadi dalam hidupnya, 2) siswa SMK memiliki pengetahuan dan keterampilan dasar dalam mengolah limbah air kelapa menjadi nata de coco. 3) siswa SMK dapat memulai membuka peluang usaha baru baik sebelum atau setelah lulus nanti.

\section{METODE PELAKSANAAN}

Mitra kegiatan ini adalah siswa SMK NU Ma'rif 01 Wanasari yang dipilih sebanyak 20 siswa yang memiliki ketertarikan dalam wirausaha bidang pangan. Kegiatan ini dilaksanakan dengan empat tahapan selama 2 bulan. Kegiatan tahap I merupakan tahapan mengukur tingkat pemahaman siswa tentang wirausaha dengan pemberian quisioner, tahap II merupakan transfer knowlegde dengan metode ceramah, tahap III dilaksanakan dengan praktek langsung menggunakan teknologi tepat guna, tahap VI merupakan tahapan evaluasi hasil kegiatan dengan metode quisioner dan ceramah.

Bahan dan alat yang digunakan pada kegiatan ini yaitu 1) quisioner untuk mengukur pemahaman siswa, 2) air kelapa yang diperoleh dari pedagang, 3) bakteri Acetobakter xylinum dalam bentuk starter yang diperoleh dari Laboratorium Program Studi S1 Teknologi Pangan UMUS Brebes, 4) bahan pendukung lain seperti cuka dapur, ZA food grade, dan gula pasir, 4) peralatan yang digunakan yaitu kompor, panci, sendok, loyang ukuran $32 \mathrm{~cm} \times 24 \mathrm{~cm}$, koran bekas, karet ikat, gayung platik, dan alat.

\section{HASIL DAN PEMBAHASAN}

\section{Tahap I}

Tahapan ini merupakan tahapan mengukur tingkat pengetahuan siswa tentang wirausaha dengan memberikan quisioner, pertanyaan dalam quisioner terdiri dari 5 pertanyaan yang di berikan pada 20 siswa. Hasil quisioner pengetahuan siswa tentang wirausaha disajikan pada tabel 1.

Berdasarkan data pada tabel 1. dapat diketahui bahwa sebagian besar siswa SMK pada kegiatan ini belum pernah mengikuti pelatihan kewirausahaan namun semua siswa memiliki keinginan yang kuat untuk menjadi wirausahawan sehingga diperlukan pelatihan kewirausahaan untuk lebih meningkatkan pengetahuan dan memotivasi siswa agar 
memiliki jiwa wirausaha, dan semua siswa berniat mengikuti pelatihan kewirausahaan. Tujuan utama pelatihan kewirausahaan yaitu membangun pola pikir, sikap, keterampilan dan membangkitkan motivasi pemuda untuk berwirausaha (Hasdar et al., 2019), sehingga pemuda memiliki karakter yang kuat menjadi modal utama menjadi seorang wirausaha dalam menghadapi tantangan perubahan yang terjadi dalam hidupnya (Utami dan Adita, 2019).

Tabel 1. Hasil quisioner pengetahuan siswa tentang wirausaha

\begin{tabular}{clcc}
\hline \multirow{2}{*}{ No } & \multicolumn{2}{c}{ Item Pertanyaan } & \multicolumn{2}{c}{ Persentase Jawaban } \\
\cline { 3 - 4 } & & Ya & Tidak \\
\hline 1 & Apakah anda pernah mendapatkan pelatihan kewirausahaan? & $100 \%$ & \\
2 & Apakah anda berniat menjadi wirausahawan? & $100 \%$ & \\
3 & Apakah anda berniat mengikuti pelatihan kewirausahaan? & $100 \%$ & \\
4 & Apakah anda pernah melakukan wirausaha offline ataupun online? & $60 \%$ & $40 \%$ \\
5 & Apakah setelah lulus nanti anda berkeinginan menjadi pegawai ? & $80 \%$ & $20 \%$ \\
\hline
\end{tabular}

Berdasarkan data hasil rekapitulasi quisioner mengenai pengetahuan siswa tentang wirausaha pada tabel 1 . ternyata $60 \%$ siswa yang mengikuti pelatihan ini sudah pernah melakukan wirausaha baik offline maupun online dan $40 \%$ lainnya belum pernah melakukan wirausaha. hal ini menunjukan bahwa $60 \%$ siswa SMK pada kegiatan ini sudah memiliki mental wirausaha yang selanjutnya harus diperkuat dalam pelatihan kewirausahaan. Mental yang kuat merupakan salah satu karakteristik wirausahawan (Maulida et al., 2016). Mental ini harus terus diasah karena berdasarkan tabel 1. pada pertanyaan nomor 5 ternyata siswa SMK masih memiliki keinginan tinggi untuk menjadi pegawai yaitu $80 \%$. Motivasi dan mental menjadi pegawai yang tinggi akan mengeliminir mental wirausahawan sehingga siswa SMK harus sering diberikan pelatihan kewirausahawan (Hasdar et al., 2018).

\section{Tahap II}

Tahapan ini merupakan transfer knowlegde pada siswa tentang membangun wirausaha bidang pangan terutama memanfaatkan limbah air kelapa menjadi nata de coco.

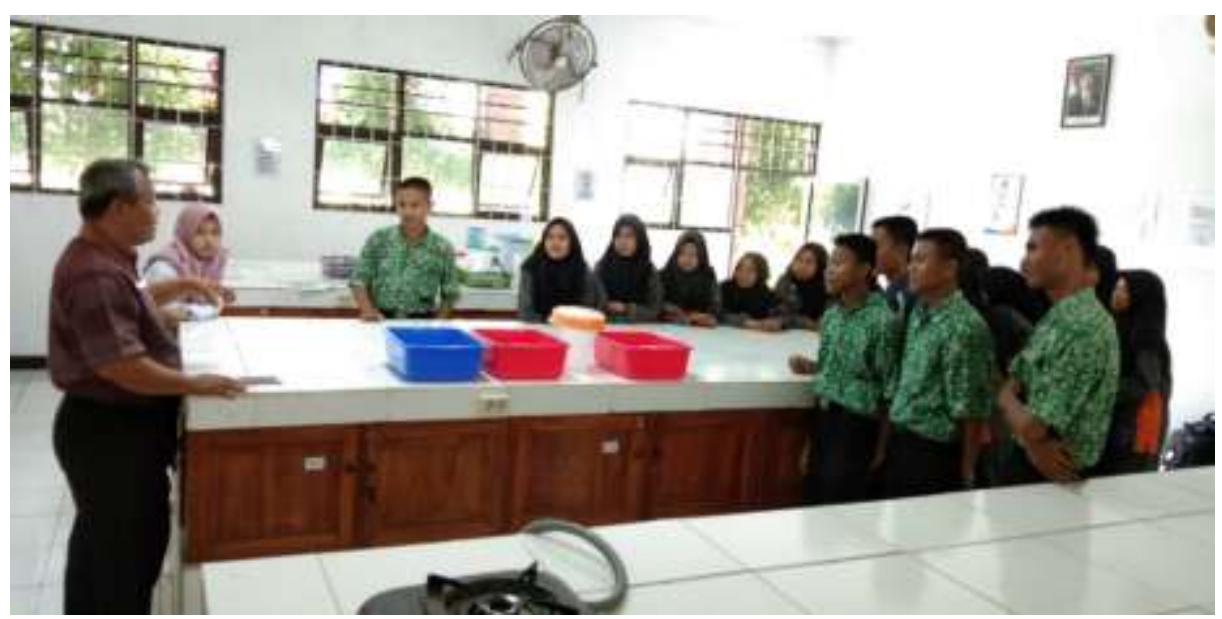

Gambar I. Siswa diberikan pemahaman tentang wirausaha bidang pangan dengan memanfaatkan potensi lokal yang mudah didapatkan 
(Sumber : doc. Pribadi, 2019)

Proses transfer knowlegde yang diberikan yaitu 1) pemahaman tentang potensi yang dimiliki oleh daerah Kabupaten Brebes baik sumber daya alam ataupun sumberdaya manusia. 2) potensi limbah air kelapa yang melimpah. 3) motensi pasar di Kabupaten Brebes. 4) modal awal yang dibutuhkan untuk wirausaha bidang pangan tidak besar sehingga siswa dapat memulainya sejak masih SMK. 5) cara melakukan pembukuan keuangan secara sederhana. 6) cara memulai wirausaha. 7) memperkenalkan natural science yang salah satunya adalah bioteknologi pangan. Natural science kadang dianggap sebagai ilmu yang sulit dipelajari, tapi dengan praktek langsung maka siswa akan lebih senang dan mudah memahami (Masrikhiyah, 2019).

Pada tahapan transfer knowlegde juga bertujuan untuk memotivasi siswa agar memiliki pola pikir berwirausaha setelah lulus nanti atau memulai wirausaha kecilkecilan saat masih sekolah sehingga semangat dan jiwa wirausaha tidak hilang.

\section{Tahap III}

Tahapan ini merupakan praktek langsung menggunakan teknologi tepat guna untuk mengahasilkan produk yang layak dipasarkan. Pada tahapan ini siswa diberi pengetahuan tentang 1) kualitas air kelapa yang di butuhkan, 2) kebersihan peralatan yang digunakan, 3) peralatan yang utama yang digunakan untuk memproduksi nata de coco, 4) kualias bibit atau starter yang digunakan, 5) metode pembuatan nata de coco, dan 6) cara pengemaan yang layak jual.

Air kelapa yang akan digunakan dalam produksi nata de coco disaring terlebih dahulu untuk menghilangkan kotoran yang terlarut. kemudian dikakukan proses pemasakan air kelapa hingga mendidih. Tujuan proses pemasakan yaitu agar bakteri kontaminan tidak mengganggu proses berikutnya sehingga hanya bakteri Acetobacter xylinum yang tumbuh dalam media pembuatan nata tersebut (Hamad, et al., 2014).

Air kelapa yang sudah mendidih dan ditambah gula pasir, ZA food grade serta cuka makan kemudian dituang dalam nampan-nampan datar agar nata yang terbentuk nantinya memiliki ukuran yang cukup lebar. Nampa-nampan nampan datar terlebih dahulu di dutup dengan koran bekas yang diikat dengan karet pada tepi bibir nampan. Penutupan media dengan koran bekas agar udara atau oksigen dapat masuk melalui pori-pori koran sehingga bakteri Acetobakter Xylinum dapat tumbuh dengan baik, karena bakteri Acetobakter Xylinum merupakan bakteri aerob, yang tumbuh pada temperatur $28-30^{\circ} \mathrm{C}$ dengan $\mathrm{pH} 4-4,5$ (Lubis dan Harahap, 2018).

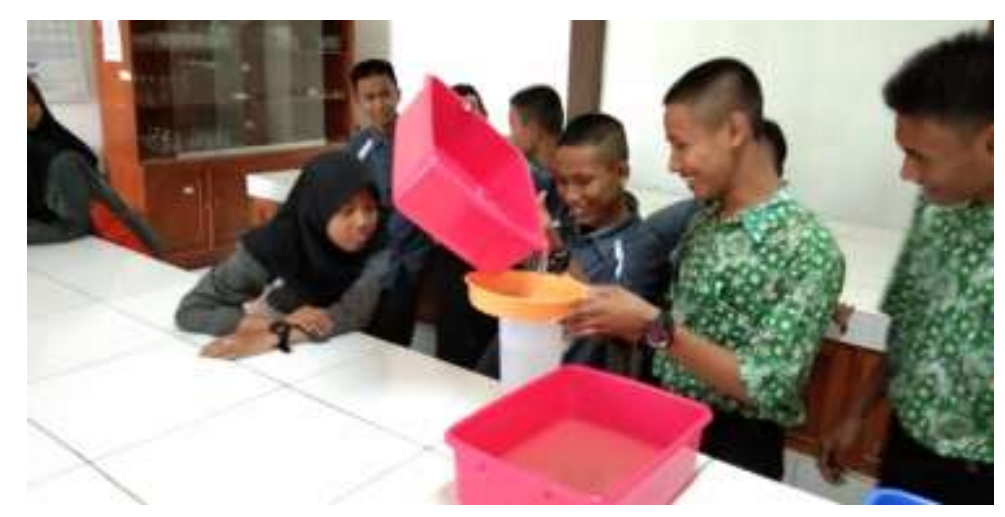

Gambar II. Siswa mempraktekan cara penyaringan air kelapa (Sumber : doc. Pribadi, 2019) 


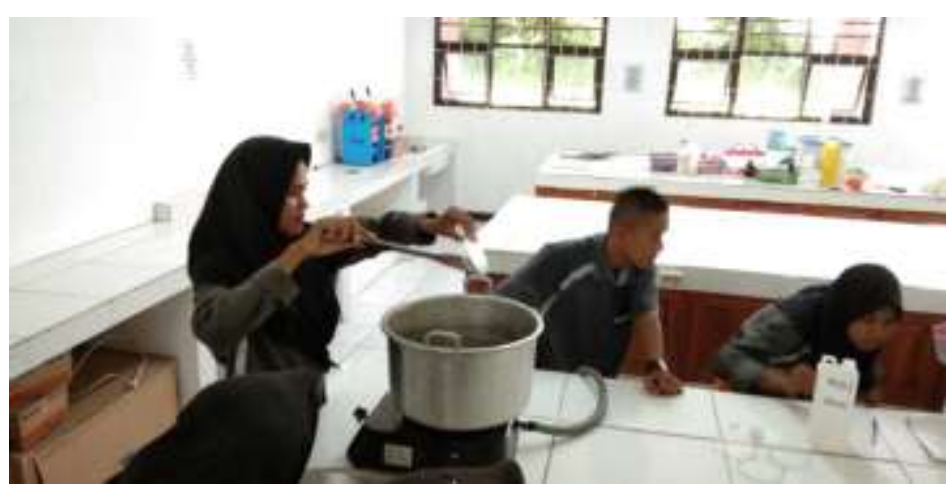

Gambar III. Siswa mempraktekan tahapan perebusan air kelapa (Sumber : doc. Pribadi, 2019)

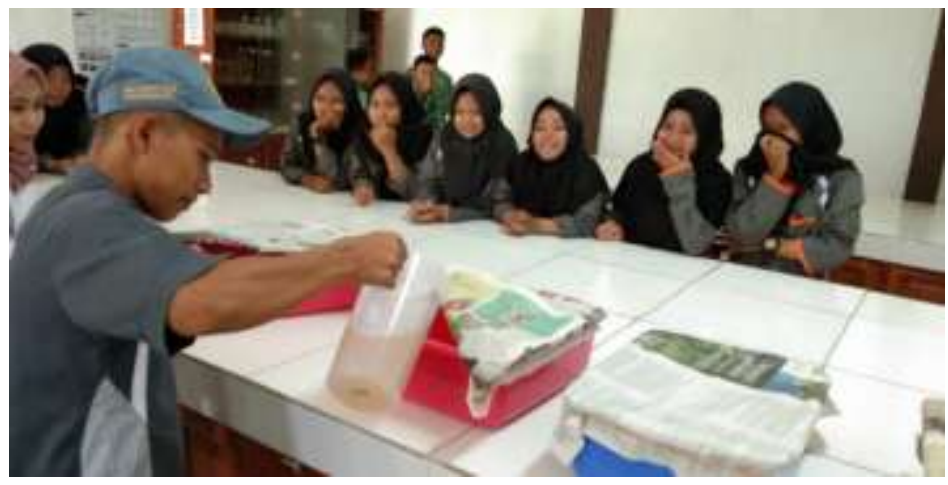

Gambar III. Siswa mempraktekan tahapan memasukan rebusan air kelapa dan starter Acetobakter Xylinum

(Sumber : doc. Pribadi, 2019)

Air kelapa yang telah dimasak sampai mendidih ditunggu sampai temperaturnya turun kemudian dituang ke nampan agar menjadi media nata, selanjutkan didiamkan selama 5 jam agar media nata temperaturnya turun (dingin) kemudian ditambahkan starter nata yang mengandung Acetobakter Xylinum sebanyak 2 sendok makan atau $\pm 30 \mathrm{ml}$ untuk satu nampan yang berisi 2 liter air kelapa. Bakteri Acetobakter Xylinum berperan dalam pembentukan selulosa berbentuk serat nata selama proses inkubasi (Ifadah et al., 2016).

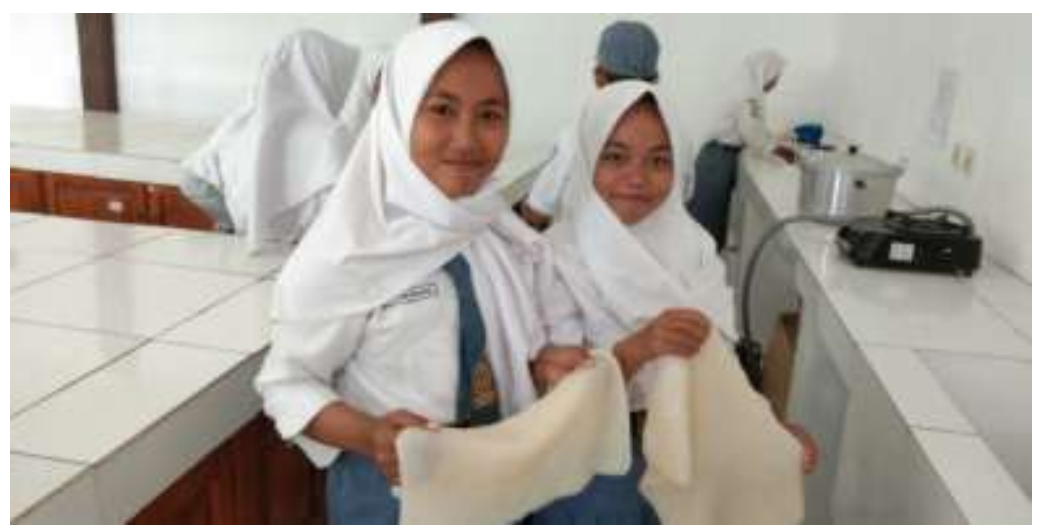

Gambar IV. Siswa melakukan pemanenan lemabaran Nata de coco (Sumber : doc. Pribadi, 2019)

Muh. Hasdar: Penumbuhan Jiwa Wirausaha Siswa SMK Ma'arif $\mathcal{N} V 01$ Wanasari Melalui Pelatihan Pengolahan Limbah Air Kelapa 
Lama waktu inkubasi selama 12 hari kemudian dipanen dalam bentuk lembaran dengan ketebalan $\pm 2 \mathrm{~cm}$. Proses pemanenan setelah lapisan selulosa terbentuk pada permukaan media. Lembaran nata yang sudah siap panen kemudian dicuci dengan bersih untuk menghilangkan lapisan tipis yang masih menempel dan mengurangi asam. Nata kemudian direndam selama 3 hari dengan mengganti air rendaman dengan yang baru. Pada hari ketiga nata dicuci sampai bersih kemudian dipotong menjadi kubus lalu direbus sampai mendidih, air rebusan dibuang dan direbus kembali dengan air yang baru. Pada perebusan terakhir ditambahkan asam sitrat sebanyak satu sendok. Penambahan asam sitrat berfungsi untuk memperkuat dan mempertahankan flavor serta menghambat pertumbuhan kapang (Rosyida, 2014).

Nata de coco yang telah di potongpotong berbentuk kubus kecil kemudian dicampur dengan larutan gula lalu dididihkan selama 15-20 menit selanjutnya didiamkan selama 12 jam agar terjadi proses penyerapan gula ke dalam nata de coco. Tahapan terakhir yaitu pengemasan dengan menggunakan cup sealer dimana siswa SMK melakukan praktek langsung proses pengemasan. Fungsi utama pengemasan nata de coco yaitu sebagai pelindung yang melindungi produk, baik dari pengaruh luar maupun dalam, fungsi lainnya adalah meningkatkan nilai tambah makanan yang dikemas melalui penampilan kemasan yang menarik dan layak jual (Mukhtar dan Nurif, 2015).

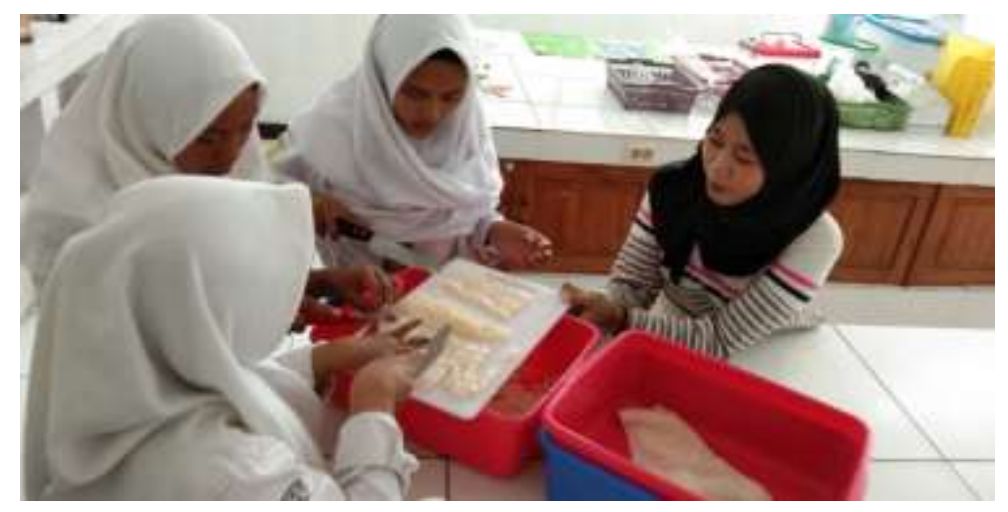

Gambar V. Siswa mempraktekan proses pengecilan ukuran nata de coco agar mudah dikonsumsi (Sumber : doc. Pribadi, 2019)
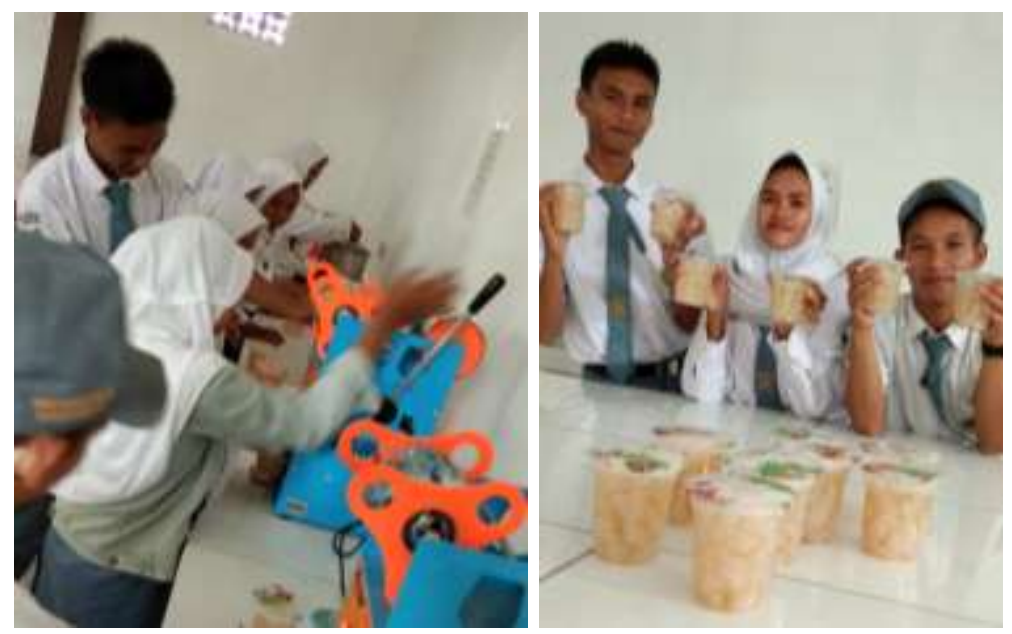

Gambar VI. Siswa mempraktekan proses pengemasan nata de coco (Sumber : doc. Pribadi, 2019)

Muh. Hasdar: Penumbuhan Jiwa Wirausaha Siswa SMK Ma'arif $\mathcal{N} U 01$ Wanasari Melalui Pelatihan Pengolahan Limbah Air Kelapa 


\section{Tahap IV}

Tahapan ini merupakan tahapan evaluasi hasil kegiatan yang berbentuk evaluasi efektifitas kegiatan pengabdian masyarakat siswa dalam mengikuti kegiatan.

Berdasarkan tabel 2 terlihat bahwa $85 \%$ peserta sangat senang dan puas akan kegiatan ini, karena kegiatan ini menambah pengetahuan mereka dan juga menguatkan jiwa kewirausaha yang mereka miliki. Kegiatan pelatihan kewirausaan merupakan salah cara untuk mengembangkan motivasi dan minat serta melahirkan ide-ide baru dari pemuda untuk terjun ke dunia wirausaha pengabdian masyarakat ini telah sukses dilaksankan, hal ini terlihat dari hasil respon siswa SMK yang menunjukan $80 \%$ sangat puas dengan kegiatan ini, yang berarti bahwa kegiatan pelatihan kewirausahaan ini telah menambah wawasan, keterampilan dan meningkatakan mentalitas menjadi wirausahaawan dan lebih produktif. Siswa SMK dapat meningkatkan kemampuan berpikir, dan keterampilan untuk menjadi lebih produktif dapat dilakukan dengan mengikuti pelatihan kewirausahaan (Gayatri dan Rahayu, 2015).

(Firdaus dan Hasanah, 2018). Kegiatan

Tabel 2. Hasil penilaian respon siswa SMK terhadap efektifitas kegiatan pengabdian masyarakat

\begin{tabular}{|c|c|c|c|c|c|}
\hline \multirow{2}{*}{ No. } & \multirow{2}{*}{ PERNYATAAN } & \multicolumn{4}{|c|}{ Persentase Jawaban } \\
\hline & & SS & $\mathbf{S}$ & TS & STS \\
\hline 1. & $\begin{array}{l}\text { Saya merasa senang dan puas dengan kegiatan pengabdian } \\
\text { masyarakat yang diselenggarakan dosen Program Studi S1 Ilmu } \\
\text { dan Teknologi Pangan UMUS Brebes }\end{array}$ & $85 \%$ & $15 \%$ & & \\
\hline 2. & $\begin{array}{l}\text { Kegiatan pengabdian masyarakat yang diselenggarakan Program } \\
\text { Studi S1 Ilmu dan Teknologi Pangan UMUS Brebes sesuai dengan } \\
\text { harapan saya }\end{array}$ & $80 \%$ & $20 \%$ & & \\
\hline 3. & $\begin{array}{l}\text { Personil/anggota yang terlibat dalam kegiatan pengabdian } \\
\text { masyarakat memberikan pelayanan sesuai dengan kebutuhan saya } \\
\text { untuk dalam membangun jiwa kewirausahaan }\end{array}$ & $85 \%$ & $15 \%$ & & \\
\hline 4. & $\begin{array}{l}\text { Setiap pertanyaan/keluhan/ permasalahan yang saya ajukan } \\
\text { ditindaklanjuti dengan baik oleh narasumber/anggota yang terlibat }\end{array}$ & $90 \%$ & $10 \%$ & & \\
\hline 5. & $\begin{array}{l}\text { Jika kegiatan ini diselenggarakan kembali, saya bersedia untuk } \\
\text { berpartisipasi/terlibat }\end{array}$ & $85 \%$ & $15 \%$ & & \\
\hline
\end{tabular}

Keterangan $:$ SS $=$ Sangat Setuju, $\mathrm{S}=$ Setuju, TS $=$ Tidak Setuju, STS = Sangat Tidak Setuju

Berdasarkan pertanyaan ke 3 dan ke 4 pada tabel 2 menunjukan bahwa siswa secara umum menilai personil atau anggota tim pengabdian masyarakat telah memberikan pemahaman dengan baik melalui komunikasi interpersonal dalam membangun jiwa kewirausaahaan siswa, hal ini terlihat dari respon yang tinggi akan keterlibatan dan pelayanan anggota tim pengabdian masyarakat. Kemampuan komunikasi interpersonal dari tim pengabdian masyarakat pasti akan memberikan dampak psikologi terhadap jiwa kewirausahaan, sehingga lebih percaya diri terhadap kemampuan wirausaha yang dimiliki (Suseno, 2009). Jika pelatihan lanjutan akan dilaksanakan hampir semua siswa bersedia ikut kembali, hal ini terlihat pada tabel 2 dimana $85 \%$ sangat ingin mengikuti kembali kegiatan lanjutan. Tingginya animo siswa SMK untuk menggikuti kembali kegiatan lanjutan tidak lepas meningkatnya pemahaman siswa akan 
pentingnya meningkatkan keterampilan dan pengetahuan akan kewirausahaan. Pada prinsipnya program kewirausahaan akan membangun pengetahuan dan keterampilan serta menuntut siswa SMK untuk terlibat dalam praktek (Christanti, 2016).

\section{Kesimpulan}

Berdasarkan hasil tahapan kegiatan dapat disimpulkan bahwa 1) kegiatan pelatihan kewirausahaan ini dapat membangun karakter yang kuat bagi siswa SMK untuk menjadi seorang wirausaha dalam menghadapi tantangan perubahan yang terjadi dalam hidupnya, 2) kegiatan pelatihan ini memberikan keterampilan pada siswa SMK dalam mengolah limbah air kelapa menjadi nata de coco, 3) Akhir kegiatan ini adalah pengemasan nata de coco yang selanjutnya siapa untuk dipasarkan sehingga siswa SMK dapat memulai membuka peluang usaha baru baik sebelum atau setelah lulus nanti dengan memasarkan produk nata de coco yang telah dipelajari. Hasil evaluasi kegiatan pelatihan kewirausahaan siswa SMK sangat senang dan puas serta sesuai harapan siswa SMK untuk membangun jiwa wirausaha yang mereka miliki.

\section{REFERENSI}

Christanti, A. 2016. Studi Peranan Pelatihan Kewirausahaan Terhadap Pembentukan Sikap Dan Intensi Kewirausahaan di Sentra Industri Produk Roti Dan Kue Rungkut Lor, Surabaya. Agora. Vol 4 (1) : 242248

Firdaus V., dan Hasanah, H., 2018. Pengaruh Pelatihan dan Pendidikan Kewirausahaan Terhadap Motivasi Berwirausaha Pada Penyandang Disabilitas di Kabupaten Jember. Fenomena. Vol ,17 (2) : 263-286

Gayatri, A. M., dan Rahayu, E. I. 2015. Pemberdayaan Siswa SMK Melalui Pelatihan Keterampilan Dengan
Pemanfaatan Kain Perca Sebagai Peluang Usaha. Sosio e-Kons. Vol. 7 (3): 210-215

Hamad, A., N. A. Handayani, dan E. Puspawiningtyas. 2014. Pengaruh umur starter Acetobacter xylinum terhadap produksi nata de coco. Techno 15(1): 37-49.

Hasdar, M., Fera, M., dan Syaifulloh, M. 2019. Pemberdayaan Kelompok Bisnis Mahasiswa Berbasis IPTEK Melalui Program Agrofood Technopreneur. Jurnal Solma, 08(1): 73-79.

Hasdar, M., Fera, M. dan Adita, M.D. 2018. Peningkatan Pengetahuan dan Skill Bisnis Calon Wirausahawan Muda di SMK Jurusan Teknologi Pengolahan Hasil Pertanian (TPHP) di Warungpring Kabupaten Pemalang. Proceeding SNK-PPM vol 1 (1), : 516-522.

Lubis, A.W., dan Harahap D.N. 2018. Pemanfaatan Sari Buah Naga Super Merah (Hylocereus costaricensis) Pada Pembuatan Nata De Coco Terhadap Mutu Fisik Nata. CHEDS: Journal of Chemistry, Education, and Science. Vol. 2 (2). 1-10

Ifadah, R.A., Kusnadi J., dan Wijayanti S.D. 2016. Strain Improvement Acetobacter xylinum Menggunakan Ethyl Methane Sulfonate (EMS) Sebagai Upaya Peningkatan Produksi Selulosa Bakteri. Jurnal Pangan dan Agroindustri Vol. 4 (1) : 273-282

Masrikhiyah, R. (2019). Peningkatan Mutu Pengetahuan Siswa Mengenai Natural Science di MI Ikhsaniyah Kupu: Pengenalan dan Praktik Penggunaan Mikroskop. Randang Tana: Jurnal Pengabdian Masyarakat. 2 (1) : 39-45

Maulida, A.N., Kusumah, I.H. , dan Permana T. (2016). Karakteristik Sikap Mental Wirausaha Mahasiswa Dalam Bidang Otomotif. Journal of 
Mechanical Engineering Education. Vol. 3 (1). 9-15

Mukhtar, S., dan Nurif, M. 2015. Peranan Packaging Dalam Meningkatkan Hasil Produksi Terhadap Konsumen. Jurnal Sosial Humaniora, Vol 8 (2). 181-191

Nurdyansyah, F., dan Widyastuti D.A. 2017. Pengolahan Limbah Air Kelapa Menjadi Nata De Coco Oleh Ibu Kelompok Tani di Kabupaten Kudus. Jurnal Kewirausahaan Dan Bisnis. Vol 21 (11) : 22-30

Rosyida, F., 2014.Pengaruh Jumlah Gula dan Asam Sitrat Terhadap Sifat Organoleptik, Kadar Air dan Jumlah
Mikroba Manisan Kering Siwalan (Borassus Flabellifer). Vol. 03 (1): 297-307.

Suseno, M. N. 2009. Pengaruh Pelatihan Komunikasi Interpersonal Terhadap Efikasi Diri Sebagai Pelatih pada Mahasiswa. Jurnal Intervensi Psikologi, Vol. 1 (1) : 93-106

Utami, S.N dan Adita, M.D. (2019). Pengenalan Analisis Break Even Point (BEP) Sebagai Bekal Bagi Mahasiswa Ilmu dan Teknologi Pangan Dalam Menumbuhkan Jiwa Wirausaha. Randang Tana: Jurnal Pengabdian Masyarakat. 2 (1) : 5460 